\title{
Polyamine Plays a Role in Subculture Growth of in Vitro Callus of Indica Rice
}

\author{
Yanping Tan, Wen Hu, Xin Xu, Jie Zhou, Chuntai Wang, Xuegun liu \\ AND GANG CHENG* \\ Hubei Provincial Key Laboratory for Protection and Application \\ of Special Plants in Wuling Area of China, College of Life Science, \\ South Central University for Nationalities, Wuhan, Hubei, 430074, China
}

Received March 12, 2016; revision accepted January 2, 2017

\begin{abstract}
In vitro embryogenic callus is a critical factor for genetic transformation of rice, especially for indica varieties. In this study, we investigated the relationship between polyamines, including putrescine (Put), spermidine (Spd) and spermine (Spm), and callus browning, and we studied the effect of exogenous Put on callus regeneration and on the content of endogenous polyamines. In addition, the expression levels of arginine decarboxylase gene $(A d c 1)$ and S-adenosylmethionine decarboxylase gene (Samdc) in embryogenic callus were studied by quantitative Real-time PCR analysis. The results showed that the contents of endogenous Put and Spd in the browning callus were significantly lower than those in normal callus. Exogenous Put could effectively improve the growing state of callus of indica rice and enhance the development of embryogenic callus. The content of endogenous polyamines in embryogenic callus, especially Spd and Spm, was increased after addition of exogenous Put. Additionally, exogenous Put also had an obvious impact on the expression levels of Adc1 but partial effect on the expression levels of Samdc gene. This study could increase the knowledge of both embryogenic callus induction and polyamine catabolism in callus in indica rice.
\end{abstract}

Keywords: browning, callus, gene expression, indica rice, polyamine

\section{INTRODUCTION}

Plant tissue culture systems have been widely used in many areas of plant science and crop improvement. Successful application of plant tissue culture techniques for crop improvement and transformation needs suitable plant regeneration methods. Generally, it is not easy to culture and regenerate monocot plants, including agronomically important crops such as rice or maize. Up to now, there have been many reports of successful plant regeneration from callus of different rice varieties, nevertheless, information about utilizing tissue culture for rice indica variety is limited (Ge et al., 2006; Rachmawati and Anzai, 2006; Priya et al., 2011; Wani et al., 2011). One of the reasons for this phenomenon was that the embryonic callus of indica rice cultivars was easier to brown than that of japonica rice cultivars, whose genomic background differs from that of indica rice cultivars (Sang and Ge, 2007; Saika and Toki, 2010). As one of important rice cultivars, indica-type rice provides staple food for almost half of the world population (Datta and Datta, 2006). To satisfy the growing demand of the ever-increasing population, more production improvement and deeper research on indica-type rice are needed. The applicable plant tissue culture methods should be carried out for producing embryonic callus cultures, which are genetically resistant to browning in indica rice.

Polyamine $(\mathrm{Pa})$ is a universal kind of low molecular weight nitrogenous alkali in fat family in plant, including putrescine (Put), spermidine (Spd), spermine (Spm) and cadaverine (Cad). Polyamine controls some processes of development and growth, for example, stimulating cell growth, differentiation and proliferation, accelerating somatic cell embryogenesis, promoting root age and development of flower, boosting up plant resistance to environmental stress (Kusano et al., 2008; Cheng et al., 2009; Fuell et al., 2010). The degradation product of polyamine can also induce hypersensitivity feedback and accelerate the ability of disease resistance in plant (Yoda et al., 2003). In addition, polyamines could delay senescence and

\footnotetext{
* Corresponding author, email: cheng_gang@aliyun.com
} 
programmed cell death (PCD) in plants. Therefore, exogenous PA application or PA overexpression in plant can promote somatic cell embryogenesis in callus by changing the level of endogenous hormone, whereas the inhibitor of polyamine can postpone or restrain somatic cell embryogenesis in callus by inhibiting polyamine biosynthesis (Torné et al., 1994; Gray et al., 1995; Takeda et al., 2002). However, little is known about the content changes of endogenous polyamines and the relation between rice callus and endogenous polyamines during indica rice callus subculture.

In plants, arginine decarboxylase (ADC), ornithine decarboxylase (ODC), and S-adenosylmethionine decarboxylase (SAMDC) are three key enzymes in the endogenous polyamine synthesis pathway (Pillai and Akiyama, 2004; Kusano et al., 2008; Hu et al., 2012). Putrescine could be synthesized directly from ornithine by the action of ODC (Hiatt et al., 1986) or synthesized indirectly from Arginine by ADC (Walden et al., 1997). The function of SAMDC is to provide decarboxylated AdoMet in spermidine biosynthesis for the aminopropyltransferases (Hanzawa et al., 2002). It was reported that $\mathrm{ADC}$ may regulate tobacco callus growth during early and late biosynthesis of Put while SAMDC mRNAs are translationally regulated by spermidine and spermine (Takeda et al., 2002; Capell et al., 2004; Pillai and Akiyama, 2004). Despite research efforts, the expression module of endogenous polyamine synthesis genes in indica rice embryonic callus during callus subculture was unclear.

In this study, we detected the content changes of the polyamine (mainly including Put, Spm, Spd) by a HPLC method, and analyzed the state of callus growth during callus subculture to study the relation between endogenous polyamine and callus growth. Then with exogenous Put treatment, the state of callus growth was valued by the sliced tissue and endogenous polyamine was also analyzed by a HPLC method. In addition, mRNA expression levels of Adc1 and Samdc in embryogenic callus were investigated using realtime fluorescence quantitative PCR analysis. This research could be helpful to clarify the mechanism of polyamines regulating rice callus growth, and to further establish efficient callus from mature embryos of indica rice.

\section{MATERIALS AND METHODS}

\section{PLANT MATERIAL}

Yuetai B (YTB), Honglian-CMS maintainer, a typical Oryza sativa subsp. indica, was obtained from National Key Laboratory of Hybrid Rice, College of Life Science, Wuhan University, China.

\section{CALLUS INDUCTION AND REGENERATION}

Rice callus was induced and regenerated in solid following the method of Lin and Zhang (2005), the basic culture medium was N6 culture medium with $2.0 \mathrm{mg} / \mathrm{l}$ 2,4-dichlorophenoxyacetic acid (2,4-D), $2.0 \mathrm{mg} / \mathrm{l} \mathrm{kinetin} \mathrm{(Kin),} 500 \mathrm{mg} / \mathrm{l}$ proline, $500 \mathrm{mg} / \mathrm{l}$ glutamine, $800 \mathrm{mg} / \mathrm{l}$ casein hydrolysate and $3 \%$ maltose, $\mathrm{pH}$ 5.9. YTB callus was cultured in the regeneration culture medium with addition of exogenous Put $(30 \mathrm{mg} / \mathrm{l})$ for 20 days. All of the calli were cultured in a growth chamber under light $\left(1800 \mu \mathrm{mol} \cdot \mathrm{m}^{-2} \cdot \mathrm{s}^{-1}\right)$ at $28 \pm 1^{\circ} \mathrm{C}$.

\section{HISTOLOGICAL ANALYSIS OF RICE CALLUS}

Rice calli were fixed in $4 \%$ formamide in PBS buffer overnight, before dehydration through a gradient series of ethanol. The samples were finally embedded in $100 \%$ Paraplast (Sigma, St. Louis, MO, USA) at $55-60^{\circ} \mathrm{C}$ and $7-9 \mu \mathrm{m}$ thick sections were prepared using a rotary-microtome. Sections were stained using a $0.05 \%$ toluidine blue solution and observed through a Nikon ECLIPSE Ti (Nikon, Japan) microscope.

\section{ISOLATION AND MEASUREMENT OF ENDOGENOUS POLYAMINES}

The modification method followed the method of Flores and Galston (1982). $1.00 \mathrm{~g}$ of callus was homogenized in $5.0 \mathrm{ml} \mathrm{5 \%} \mathrm{cool} \mathrm{perchloric} \mathrm{acid}$ (V/V), extracted in ice water bath for $1 \mathrm{~h}$, spun at $15,000 \mathrm{rpm}$ for $30 \mathrm{~min}$ at $4^{\circ} \mathrm{C}, 500 \mu \mathrm{L}$ of upper clear aqueous layer was carefully transferred to another $7 \mathrm{ml}$ polypropylene tube, $1.0 \mathrm{ml}$ of $2 \mathrm{~mol} / 1$ $\mathrm{NaOH}$ and $10 \mu \mathrm{l} \alpha$-chlorobenzaldehyde were added and the preparation was mixed in vortex for $20 \mathrm{~s}$, incubated at $37^{\circ} \mathrm{C}$ in water bath for $30 \mathrm{~min}, 2.0 \mathrm{ml}$ of $\mathrm{NaCl}$ saturation solution was added and the preparation was mixed in vortex, then extracted with $3.0 \mathrm{ml}$ of aether, spun at $15,000 \mathrm{rpm}$ for $5 \mathrm{~min}$ at $4^{\circ} \mathrm{C} ; 1.0 \mathrm{ml}$ of aether phase was transferred to another new polypropylene tube and dried, dissolved with $1.0 \mathrm{ml}$ of methanol and filtrated with $0.22 \mu \mathrm{m}$ membranes. $20 \mu \mathrm{l}$ of filtrate was measured by HPLC.

The content of polyamine was measured with Agilent 1200 high performance liquid chromatography (HPLC). The parameters were as follows: Agilent ZORBAX Eclipse XDBC18 liquid phase chromatogram columniation $(4.6 \times 150 \mathrm{~mm}, 5 \mathrm{um})$, methanol : $\mathrm{H}_{2} \mathrm{O}(1: 1$, $7: 13,1: 4$ and $3: 2$ ) for gradient elution for mobile phase, $254 \mathrm{~nm}$ wavelength, $1.0 \mathrm{ml} / \mathrm{min}$ flow velocity, $25^{\circ} \mathrm{C}$ temperature of columniation, $30 \mathrm{~min}$ of the measurement time. An external standard method was used for chromatographic quantitive analysis. 
RNA EXTRACTION AND CDNA SYNTHESIS

RNA was purified from callus at different stages with TRIzol reagent (Invitrogen, USA) according to the manufacturer's instructions and we removed the genomic DNA using DNase I (TaKaRa, Japan). Total RNA was used as the template for cDNA synthesis with an M-MLV reverse transcriptase kit (TOYOBO, Japan) at $42^{\circ} \mathrm{C}$ for $1 \mathrm{~h}$.

\section{QUANTITATIVE REAL-TIME REVERSE}

TRANSCRIPTION-POLYMERASE CHAIN REACTION

(RT-PCR) ANALYSIS FOR Adc1 AND Samdc GENE

The quantitative PCR was performed in a Rotor gene 2000 PCR system (Qiagen, German) using the following primer pairs: Adc1 gene, ADC1F (5'-AGAAGCTGTCCAAGAGGGTGA-3') and ADC1R (5'-CCGATCAGTTCAAGGACGGC-3'), Samdc gene, SamdcF (5'-GGTTTGAGGGCTATGAGA-3') and SamdcR (5'-AATAGATAAACAGGCTGGACT-3'), for Actin gene, ActinF (5'-TGCTATGTACGTC GCCATCCAG-3') and ActinR (5'-AATGAGTAACCAC GCTCCGTCA-3'). The Actin gene, a single copy gene in the rice nuclear genome, was used as a control for the analysis. The PCR conditions were as follows: 40 cycles of $94^{\circ} \mathrm{C}$ for $30 \mathrm{~s}, \mathrm{Tm}$ (Actin $66^{\circ} \mathrm{C}$, Adc $162^{\circ} \mathrm{C}$, Samdc $56^{\circ} \mathrm{C}$ ) for $30 \mathrm{~s}, 72^{\circ} \mathrm{C}$ for $30 \mathrm{~s}$. Fluorescence was quantified every $1^{\circ} \mathrm{C}$ from $57^{\circ} \mathrm{C}$ to $99^{\circ} \mathrm{C}$ after PCR cycles. In all PCR experiments, amplification of a single sample was confirmed by $2^{-\triangle \Delta C T}$ analysis of real-time PCR and gel electrophoresis of PCR products. All quantitative RT-PCR experiments were performed with biologically independent samples at least three times.

\section{STATISTICAL ANALYSES}

Statistical analyses were performed with SPSS 16.0 software (SPSS Inc., Chicago, IL, USA) and Means $\pm \mathrm{SE}$ of three independent experiments with three replicates were shown in the Tables and Figures. Significant differences between the means were determined using one-way analyses of variance (ANOVAs) and the Duncan's test for multiple range comparison with significant level established at $\mathrm{P}<0.05$.

\section{RESULTS}

\section{CONTENT OF ENDOGENOUS POLYAMINES}

Endogenous polyamines of the callus were analyzed to investigate the relation between rice callus browning and endogenous polyamines. During YTB callus subculture growth, as shown in Fig. 1d, the callus gradually differentiated into two kinds on $15^{\text {th }}$ day: the normal growing callus and the browning callus. Table 1 (N6 CK group) shows that, about $70 \%$ of callus appeared brown after being subcultured for 20 days. As shown in Table 2, the contents of endogenous Put and Spd

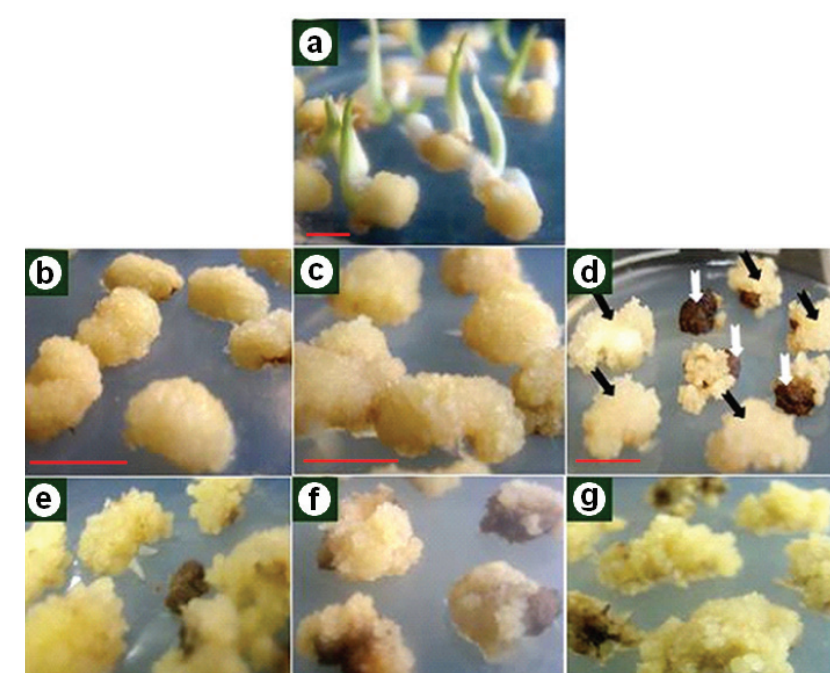

Fig. 1. Representative photographs of indica rice YTB callus in different conditions. (a) The indica rice YTB callus (induced after 8 days); (b) The indica rice YTB callus as a control (subcultured for 5 days); (c) The indica rice YTB callus treated with Put (subcultured for 5 days); (d) The indica rice YTB callus (subcultured for 15 days). The normally growing calli are marked with black arrows and the browning calli are marked with white arrows; (e) The indica rice YTB callus treated with Put (subcultured for 15 days); (f) The indica rice YTB callus as a control (subcultured for 20 days); (g) The indica rice YTB callus treated with Put (subcultured for 20 days). Bar $=5 \mathrm{~mm}$.

TABLE 1. The browning status of indica rice callus after being subcultured for 20 days.

\begin{tabular}{cccccc}
\hline \hline \multirow{2}{*}{ Variety } & \multirow{2}{*}{ Medium } & Callus number & \multicolumn{3}{c}{ Browning rate (\%) } \\
\cline { 3 - 6 } & & 50 & First degree & Second degree & Third degree \\
\hline \multirow{2}{*}{ YTB } & N6 (CK) & 50 & 24.40 & 59.40 & 16.25 \\
\cline { 2 - 6 } & N6 + Put & 79.24 & 13.21 & 7.55 \\
\hline
\end{tabular}

The first degree means that the callus browning rate is below $50 \%$, the second degree means that the callus browning rate is between $50 \%$ and $100 \%$, the third degree means complete browning. The browning rate (\%) was the percentage of the browning callus accounted for the total subculture. $(n=10)$ 
TABLE 2. Changes in endogenous polyamines content $(\mu \mathrm{g} / \mathrm{g})$ during callus subculture from mature embryos.

\begin{tabular}{cccccc}
\hline \hline Callus & Days & Put & Spd & Spm & Total Pa content \\
\hline YTB-N & 0 & $208.11 \pm 1.73$ & $52.66 \pm 1.92$ & $65.40 \pm 1.85$ & $319.24 \pm 5.46$ \\
\hline & 5 & $305.57 \pm 1.96$ & $214.65 \pm 2.35$ & $77.83 \pm 1.90$ & $594.70 \pm 5.35$ \\
\hline & 6 & $273.24 \pm 1.62$ & $220.27 \pm 2.05$ & $72.76 \pm 1.85$ & $565.14 \pm 5.61$ \\
\hline YTB-N & 10 & $242.36 \pm 1.68$ & $134.16 \pm 1.73$ & $63.53 \pm 1.73$ & $438.64 \pm 5.32$ \\
\hline YTB-B & 15 & $344.96 \pm 1.56^{* *}$ & $143.48 \pm 1.82^{* *}$ & $65.84 \pm 1.82$ & $557.52 \pm 5.21$ \\
\hline YTB-N & 20 & $314.75 \pm 1.87$ & $110.80 \pm 1.76$ & $67.92 \pm 1.90$ & $489.21 \pm 5.63$ \\
\hline YTB-B & 20 & $360.21 \pm 1.73^{* *}$ & $145.35 \pm 1.80^{* *}$ & $65.31 \pm 1.83$ & $572.43 \pm 5.42$ \\
\hline
\end{tabular}

YTB-N - normal YTB callus (not treated with Put); YTB-B - browned YTB callus (not treated with Put);

( ${ }^{*}$ for $P<0.05$ and $^{* *}$ for $P<0.01$, based on one-way ANOVA analysis). (n=3)

reached $305.57 \mu \mathrm{g} / \mathrm{g}$ and $214.65 \mu \mathrm{g} / \mathrm{g}$ on $5^{\text {th }}$ day of callus subculture, respectively. On $15^{\text {th }}$ day of callus subculture, the contents of endogenous Put $(314.75 \mu \mathrm{g} / \mathrm{g})$ and Spd (110.80 $\mu \mathrm{g} / \mathrm{g})$ in the browning callus were obviously lower than those of normal callus. Also, endogenous Put $(315.89 \mu \mathrm{g} / \mathrm{g})$ and Spd ( $108.40 \mu \mathrm{g} / \mathrm{g})$ in the browning callus were significantly lower than those of normal callus on $20^{\text {th }}$ day. On the other hand, endogenous Spm in the browning callus did not differ from that in normal callus. Therefore, exogenous Put (30 mg/l) was added to rice callus culture to raise the polyamines concentrations and study the effort on rice callus.

\section{EXOGENOUS PUT EFFECT ON THE GROWTH STATE OF CALLUS}

In order to obtain better callus and define the effect of exogenous Put on callus during callus subculture, exogenous Put (30 $\mathrm{mg} / \mathrm{l})$ was added to the callus subculture medium. The growth state of the subcultured callus was observed to be different in the rice callus treated with exogenous Put from that in the control callus. As shown in Fig. 1, the rice callus treated with exogenous Put (Figs. 1c, 1e, 1g), was more compact, had a faster growth rate and a lower browning rate than that of the control callus (Fig. 1b, 1d, 1f). After 20 days of subculture, the calli treated with exogenous Put showed less browning and alighter color than the control (Fig. 1g). As shown in Fig. 2, after 20 days of subculture, the embryogenic callus treated with Put had a smaller cell size, was more uniform in cell shape and denser in cell quality, and it was more deeply stained with toluidine blue than the control embryogenic callus. Moreover, according to the browning rate statistics of callus subcultured for 20 days, the callus treated with exogenous Put had a lower browning rate than the control callus (Table 2 ).

\section{EXOGENOUS PUT EFFECT ON THE CONTENT OF ENDOGENOUS PUT}

In order to define the effect of exogenous Put on endogenous Put in callus, the content of endogenous Put was analyzed by HPLC during callus

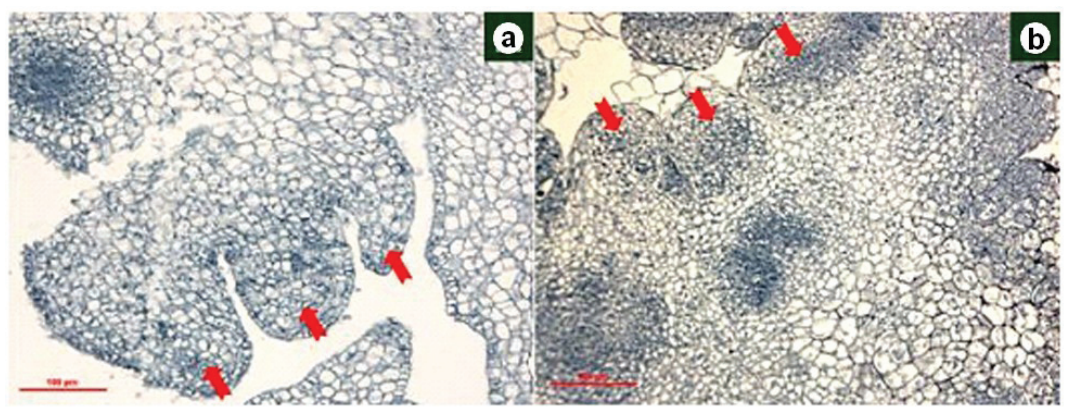

Fig. 2. Representative photographs of the embryogenic callus cells of indica rice. (a) The indica rice YTB callus as a control (subcultured for 20 days), the embryogenic cells are marked with red arrows; (b) The indica rice YTB callus treated with Put (subcultured for 20 days), the embryogenic cells are marked with red arrows. Bar $=100 \mu \mathrm{m}$. 
subculture. On $5^{\text {th }}$ day of callus subculture growth, the content of endogenous Put $(440.21 \mu \mathrm{g} / \mathrm{g})$ from the callus with exogenous Put treatment was much higher than that $(305.57 \mu \mathrm{g} / \mathrm{g})$ of the control callus (Table 3 ). On $15^{\text {th }}$ day, the callus with exogenous Put treatment contained $473.13 \mu \mathrm{g} / \mathrm{g}$ Put and the control callus contained $346.49 \mu \mathrm{g} / \mathrm{g}$ Put. Finally, the content of endogenous Put (483.07 $\mu \mathrm{g} / \mathrm{g}$ ) from the callus with exogenous Put treatment was much higher than that $(380.03 \mu \mathrm{g} / \mathrm{g})$ of the control callus on $20^{\text {th }}$ day.

\section{EXOGENOUS PUT EFFECT ON THE CONTENT OF ENDOGENOUS SPD AND SPM}

On $5^{\text {th }}$ day, the contents of endogenous Spd in callus treated with exogenous Put increased to $263.43 \mu \mathrm{g} / \mathrm{g}$ while that in the control callus was $216.45 \mu \mathrm{g} / \mathrm{g}$. (Table 3 ). Then on $15^{\text {th }}$ day, the contents of endogenous Spd in callus treated with exogenous Put reached $287.68 \mu \mathrm{g} / \mathrm{g}$ while that in the control callus just reached $145.94 \mu \mathrm{g} / \mathrm{g}$. On $20^{\text {th }}$ day, the content of endogenous Spd (247.91 $\mu \mathrm{g} / \mathrm{g})$ in the callus treated with exogenous Put was significantly higher than that $(147.67 \mu \mathrm{g} / \mathrm{g})$ in the control callus. It can be concluded that exogenous Put could increase the content of endogenous Spd in the callus during callus subculture growth. Meanwhile, the content of endogenous Spm also increased in the callus treated with exogenous Put during callus subculture growth (Table 3) and reached the highest peak at $238.24 \mu \mathrm{g} / \mathrm{g}$ on $15^{\text {th }}$ day.

\section{EXOGENOUS PUT EFFECT ON THE EXPRESSION LEVEL OF Adc1 AND Samdc}

To further find out the exogenous Put effect on the expression of arginine decarboxylase gene Adc1 and S-adenosylmethionine decarboxylase gene Samdc in callus subculture, the expression level of Adc1 and Samdc gene was analyzed in the subculture at different stages (Figs. 3 and 4). Under exogenous Put (30 mg/l) treatment, the expression level of $A d c 1$ was significantly raised in callus after 10 days, while the expression of Adc1 of the control callus was significantly raised after 20 days (Fig. 3 ).

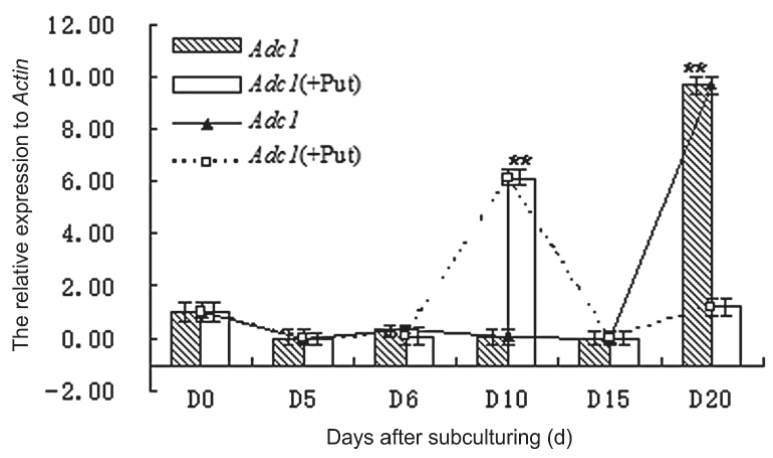

Fig. 3. Quantitative expression analysis of Adc1 in subcultured callus of indica rice at different stages $(n=3)$. Asterisks indicate that the difference in the value of relative expression between Put-treated callus cultures and the corresponding control is significant $(*$ for $P<0.05$ and ${ }^{* *}$ for $P<0.01$, based on one-way ANOVA analysis).

Table 3. Changes in endogenous polyamines contents $(\mu \mathrm{g} / \mathrm{g})$ during callus subculture with exogenous Put treatment.

\begin{tabular}{cccccc}
\hline \hline Callus & Days & Put & Spd & Spm & Total Pa content \\
\hline YTB-N & 0 & $211.11 \pm 1.65$ & $55.66 \pm 1.86$ & $64.30 \pm 1.83$ & $331.08 \pm 5.34$ \\
\hline & 5 & $305.57 \pm 1.96$ & $216.45 \pm 2.60$ & $78.23 \pm 1.95$ & $834.90 \pm 6.25$ \\
\hline & 6 & $265.81 \pm 1.54$ & $226.19 \pm 1.95$ & $72.76 \pm 1.85$ & $654.14 \pm 5.61$ \\
\hline & 10 & $222.66 \pm 1.59$ & $136.27 \pm 1.75$ & $61.71 \pm 1.84$ & $420.64 \pm 5.17$ \\
\hline YTB-Put & 15 & $346.49 \pm 1.53$ & $145.94 \pm 1.71$ & $66.33 \pm 1.80$ & $558.77 \pm 5.05$ \\
\hline & 20 & $380.03 \pm 1.66$ & $147.67 \pm 1.74$ & $64.96 \pm 1.81$ & $592.66 \pm 5.21$ \\
\hline & 0 & $213.98 \pm 1.79$ & $160.61 \pm 1.90$ & $134.84 \pm 2.02$ & $509.43 \pm 5.71$ \\
\hline & 5 & $440.21 \pm 1.70$ & $263.43 \pm 2.24$ & $179.96 \pm 2.40$ & $878.96 \pm 6.60$ \\
\hline & $355.18 \pm 1.82$ & $184.86 \pm 1.87$ & $187.48 \pm 2.27$ & $638.15 \pm 5.68$ \\
\hline & 10 & $313.38 \pm 1.50$ & $278.95 \pm 1.76$ & $211.92 \pm 1.99$ & $804.25 \pm 5.24$ \\
\hline & $473.13 \pm 2.18$ & $287.68 \pm 2.07$ & $238.24 \pm 1.91$ & $999.05 \pm 6.15$ \\
\hline
\end{tabular}

YTB-N - normal YTB callus (not treated with Put); YTB-Put - YTB callus treated with Put. (n=3) 


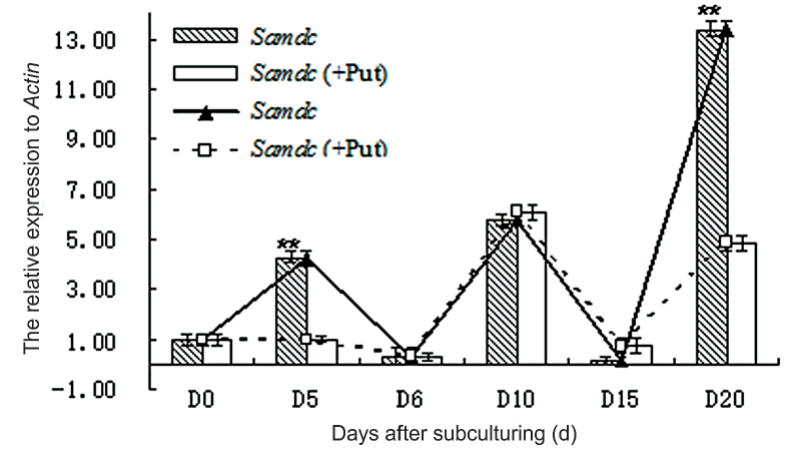

Fig. 4. Quantitative expression analysis of Samdc in subcultured callus of indica rice at different stages $(n=3)$. Asterisks indicate that the difference in the value of relative expression between Put-treated callus cultures and the corresponding control is significant (*for $P<0.05$ and **for $P<0.01$, based on one-way ANOVA analysis).

During YTB control callus subculture, the expression of Samdc gene of the control callus was significantly raised on $5^{\text {th }}, 10^{\text {th }}$, and $20^{\text {th }}$ day. Meanwhile, the expression of Samdc gene was also raised on $10^{\text {th }}$ day in the callus subculture with exogenous Put, while the content of endogenous Put, Spd and Spm also increased on $10^{\text {th }}$ day (Table 3). However, there was no perceptible change of Samdc gene expression in rice callus treated with exogenous Put.

\section{DISCUSSION}

Rice callus induction culture is one of the key steps in rice callus subculture, and the browning of rice callus could be related to the quantities of endogenous hormones (Priya et al., 2011; Wani et al., 2011). Putrescine (Put), as a kind of polyamines in plants, could protect plants from abiotic and biotic stresses (Bais and Ravishankar, 2002). In this study, the content of endogenous Put in the browning callus was obviously lower than that of normal callus during YTB callus subculture growth. In this study we also tried to add different concentrations of exogenous Put to improve the rice callus growth (data not shown). The results showed that exogenous Put caused a marked improvement in rice callus growth and reduction of callus browning. From all these data, it was concluded that exogenous Put was helpful in the callus subculture and embryonic callus could show a lower browning rate than the control callus. It was also suggested that Put could be considered as a growth regulator of YTB callus. Therefore, it could increase the regeneration capacity of rice callus and reduce the callus browning effect. However, there were also reports that the different genotypes or physiological status of plants or explants in the process of somatic embryogenesis did not have the same demand for the polyamines (Kakkar et al., 2000), and this kind of phenomenon did not appear in this research.

As for plant polyamine biosynthesis, Put is the diamine precursor and promotes the synthesis of endogenous polyamines Spd and Spm (Tiburcio et al., 1997; Bouchereau et al., 1999). In this study, the content of endogenous Spd in the browning callus was also lower than that of normal callus during YTB callus subculture growth, while the content of endogenous Spm did not significantly differ in the browning callus and the normal callus. After exogenous Put was added to rice callus culture, the content of endogenous Spd and Spm was correspondingly increased. This showed that exogenous Put treatment led to increase of the content of endogenous Put in callus during rice callus subculture growth. Thus, it was suggested that Put in YTB callus could be used as the precursor to promote the synthesis of endogenous polyamines Spd and Spm. On the other hand, it is reported that spermidine (Spd) could also protect plants from abiotic and biotic stresses (Shi and Chan, 2014). Exogenous Put and Spd have been reported to be helpful to recover browning tissues into normal callus cultures and improving plant regeneration by acting as plant growth substances (Tang et al., 2004). In this study, the content of endogenous Spd was increased by exogenous Put treatment and this implied that the increasing Spd could also act as a growth regulator of YTB callus and promote the regeneration capacity of rice callus. Therefore, the function of Spd in YTB callus needs to be analyzed in a further study.

In plants, Adc and Samdc genes had different expression patterns under different abiotic stresses, while rice Odc gene has not been confirmed yet (Alcazar et al., 2006; Kusano et al., 2008). In this study, the mRNA levels of rice Adcl gene were in agreement with the alterations of endogenous Put content in callus growth, implying that Adc1 gene was induced by exogenous Put, which agrees with other reports (Liu and Moriguchi, 2007; Liu et al., 2009). As for Samdc gene, it was reported that higher levels of putrescine could induce Samdc gene expression and promote spermidine and spermine synthesis, accordingly (Capell et al., 2004). In YTB control callus culture, Samdc gene expression was induced at the beginning and the end of callus culture $\left(5^{\text {th }}, 10^{\text {th }}, 20^{\text {th }}\right.$ day). This could be like a response to starvation stress caused by callus culture, since this kind of induction has been mentioned for a variety of plants such as peach (Liu and Moriguchi, 2007), soybean (Tian et al., 2004), and Arabidopsis (Urano 
et al., 2003). Due to inadequate endogenous Put in YTB control callus, the content of endogenous spermidine and spermine did not increase with Samdc gene expression induced on $10^{\text {th }}$ or $20^{\text {th }}$ day. By contrast, in callus treated with exogenous Put, which had higher levels of putrescine, the content of endogenous spermidine and spermine was remarkably increased with Samdc gene expression induced on $10^{\text {th }}$ day. On the basis of the above data, it was suggested that exogenous Put could induce Adc1 gene expression and partly affect the expression levels of Samdc gene, and then accelerate the synthesis of endogenous polyamines in YTB callus.

\section{CONCLUSIONS}

During the callus subculture growth, the content of endogenous Put and Spd in the browning callus was much lower than that of normal callus. It was suggested that endogenous Put and Spd could be related to browning of rice callus. Exogenous Put (30 mg/l) was added to indica rice callus subculture medium to improve the quality of the embryo callus and investigate the effect of exogenous putrescine during rice callus growth. The results showed that exogenous putrescine could effectively improve the growing state of indica rice callus and enhance the callus embryogenic traits. The content of endogenous polyamines in embryo callus, especially for $\mathrm{Spm}$ and Spd, was increased by exogenous putrescine during the callus subculturing. As for two key polyamine biosynthetic enzyme genes, Adc1 and Samdc, exogenous putrescine had an obvious impact on the expression levels of Adc1 gene and a partial effect on the expression levels of Samdc gene. Exogenous Put treatment could be a feasible method of improving the quality of the embryo callus in indica rice. These results could increase the knowledge of both indica rice embryogenic callus induction and polyamine catabolism in rice callus growth.

\section{AUTHORS' CONTRIBUTIONS}

YP Tan and G Cheng designed the research experiments. YP Tan, W Hu, X Xu, J zhou, CT Wang, $X Q$ Liu and $G$ Cheng performed the experimental research. YP Tan, $\mathrm{X} \mathrm{Xu}$, and G Cheng analyzed the data. YP Tan and G Cheng prepared and wrote the manuscript. The authors declare that there are no conflicts of interest.

\section{ACKNOWLEDGEMENTS}

This work was supported by China Scholarship Council Project for Young Outstanding Talents, the Science Foundation of State Ethnic Affairs Commission of China (14ZNZ022), the Fundamental Research Funds for the Central Universities, South-Central University for Nationalities (ZY15012) and Academic Innovation Team for Plant Development and Genetics in SouthCentral University for Nationalities.

\section{REFERENCES}

Alcazar R, Marco F, Cuevas JC, Patron M, Ferrando A, Carrasco P, Tiburcio AF, and Altabella T. 2006. Involvement of polyamines in plant response to abiotic stress. Biotechnology Letter 28(23): 1867-1876.

BAIS HP and RAVISHANKAR GA. 2002. Role of polyamines in the ontogeny of plants and their biotechnological applications. Plant Cell, Tissue and Organ Culture 69(1): 1-34.

Bouchereau A, AzIz A, LARher F, and Martin-TAnguy J. 1999. Polyamines and environmental challenges: recent development. Plant Science 140(2): 103-125.

Capell T, Bassie L, and Christou P. 2004. Modulation of the polyamine biosynthetic pathway in transgenic rice confers tolerance to drought stress. Proceedings of the National Academy of Sciences of the U.S.A. 101(26): 9909-9914.

Cheng L, Zou Y, Ding S, Zhang J, Yu X, CaO J, and Lu G. 2009. Polyamine accumulation in transgenic tomato enhances the tolerance to high temperature stress. Journal of Integrative Plant Biology 51(5): 489-499.

DATTA K, and DATTA SK. 2006. Indica rice (Oryza sativa, BR29 and IR64). Methods in Molecular Biology 343: 201-212.

Flores HE, and Galston AW. 1982. Analysis of polyamines in higher plants by high performance liquid chromatography. Plant Physiology 69(3): 701-706.

Fuell C, Elliott KA, Hanfrey CC, Franceschetti M, and MiCHAEL AJ. 2010. Polyamine biosynthetic diversity in plants and algae. Plant Physiology and Biochemistry 48(7): 513-520.

Ge X, Chu Z, Lin Y, and Wang S. 2006. A tissue culture system for different germplasms of indica rice. Plant Cell Reports 25(5): 392-402.

Gray DJ, Compton ME, Harrell RC, and Cantliffe DJ. 1995. Somatic embryogenesis and the technology of synthetic seed. In: Bajaj YPS [ed.] Somatic Embryogenesis and Synthetic Seed I, 126-151, Springer Berlin Heidelberg.

Hanzawa Y, Imai A, Michael AJ, Komeda Y, and Takahashi T. 2002. Characterization of the spermidine synthase-related gene family in Arabidopsis thaliana. FEBS Letter 527(1-3): 176-180.

Hiatt AC, McIndoo J, and Malmberg RL. 1986. Regulation of polyamine biosynthesis in tobacco. Effects of inhibitors and exogenous polyamines on arginine decarboxylase, ornithine decarboxylase, and S-adenosylmethionine decarboxylase. The Journal of Biological Chemistry 261(3): 1293-1298. 
Hu X, Zhang Y, Shi Y, Zhang Z, Zou Z, Zhang H, and ZHaO J. 2012. Effect of exogenous spermidine on polyamine content and metabolism in tomato exposed to salinity-alkalinity mixed stress. Plant Physiology and Biochemistry 57: 200-209.

Kakkar RK, Nagar PK, AHUJa PS, and Rai VK. 2000. Polyamines and plant morphogenesis. Biologia Plantarum 43(1): 1-11.

Kusano T, Berberich T, Tateda C, and Takahashi Y. 2008. Polyamines: essential factors for growth and survival. Planta 228(3): 367-381.

LIN YJ, and ZHANG Q. 2005. Optimising the tissue culture conditions for high efficiency transformation of indica rice. Plant Cell Reports 23(8): 540-547.

LiU JH, Ban Y, Wen XP, NaKajima I, and Moriguchi T. 2009. Molecular cloning and expression analysis of an arginine decarboxylase gene from peach (Prunus persica). Gene 429(1-2): 10-17.

LiU JH, and Moriguchi T. 2007. Changes in free polyamine titers and expression of polyamine biosynthetic genes during growth of peach in vitro callus. Plant Cell Reports 26(2): 125-131.

Pillai MA, and AkiYama T. 2004. Differential expression of an S-adenosyl-L-methionine decarboxylase gene involved in polyamine biosynthesis under low temperature stress in japonica and indica rice genotypes. Molecular Genetics Genomics 271(2): 141-149.

PRIYA AM, PANDIAN SK, and RAMESh M. 2011. Efficient in vitro plant regeneration through leaf base derived callus cultures of abiotic stress sensitive popular Asian indica rice cultivar IR 64 (Oryza sativa L.). Acta Biologica Hungarica 62(4): 441-452.

RACHMAWATI D, and Anzai H. 2006. Studies on callus induction, plant regeneration and transformation of Javanica rice cultivar. Plant Biotechnology 23(5): 521-524.

SAIKA H, and TOKI S. 2010. Mature seed-derived callus of the model indica rice variety Kasalath is highly competent in Agrobacterium-mediated transformation. Plant Cell Reports 29(12): 1351-1364.

SANG T, and GE S. 2007. Genetics and phylogenetics of rice domestication. Current Opinion in Genetics and Development 17(6): 533-538.
SHI H, and CHAN Z. 2014. Improvement of plant abiotic stress tolerance through modulation of the polyamine pathway. Journal of Integrative Plant Biology 56(2): 114-121.

TAKeda T, Hayakawa F, OE K, and MatsuOKa H. 2002. Effects of exogenous polyamines on embryogenic carrot cells. Biochemical Engineering Journal 12(1): 21-28.

TANG W, Newton RJ, and Outhavong V. 2004. Exogenously added polyamines recover browning tissues into normal callus cultures and improve plant regeneration in pine. Physiologia Plantarum 122(3): 386-395.

Tian AG, ZhaO JY, Zhang JS, Gai JY, and Chen SY. 2004. Genomic characterization of the S-adenosylmethionine decarboxylase genes from soybean. Theoretical and Applied Genetics 108(5): 842-850.

Tiburcio AF, Altabella T, Borrell A, and Masgrau C. 1997. Polyamine metabolism and its regulation. Physiologia Plantarum 100(3): 664-674.

Torné JM, Claparols I, Marcé M, Guergué AM, and SanTOS MA. 1994. Influence of pretreatments with inhibitors of putrescine synthesis on polyamine metabolism and differentiation processes of maize calluses. Plant Science 100(1): 15-22.

Urano K, Yoshiba Y, Nanjo T, Igarashi Y, Seki M, Sekiguchi F, YAMAgUCHI-ShinozaKi K, and ShinozaKi K. 2003. Characterization of Arabidopsis genes involved in biosynthesis of polyamines in abiotic stress responses and developmental stages. Plant, Cell and Environment 26(11): 1917-1926.

Walden R, Cordeiro A, and Tiburcio AF. 1997. Polyamines: small molecules triggering pathways in plant growth and development. Plant Physiology 113(4): 1009-1013.

Wani SH, Sanghera GS, and Gosal SS. 2011. An efficient and reproducible method for regeneration of whole plants from mature seeds of a high yielding Indica rice (Oryza sativa L.) variety PAU 201. New Biotechnology 28(4): 418-422.

Yoda H, Yamaguchi Y, and Sano H. 2003. Induction of hypersensitive cell death by hydrogen peroxide produced through polyamine degradation in tobacco plants. Plant Physiology 132(4): 1973-1981. 